\title{
Recent US Patterns and Predictors of Prevalent Diabetes among Acute Myocardial Infarction Patients
}

\author{
Bruce Ovbiagele, ${ }^{1}$ Daniela Markovic, ${ }^{2}$ and Gregg C. Fonarow ${ }^{3}$ \\ ${ }^{1}$ Department of Neurosciences, University of California at San Diego, 9500 Gilman Drive, no. 9127, San Diego, CA 92093, USA \\ ${ }^{2}$ Department of Biomathematics, Ronald-Reagan-UCLA Medical Center, Los Angeles, CA 90095, USA \\ ${ }^{3}$ Division of Cardiology and Department of Medicine, Ronald-Reagan-UCLA Medical Center, Los Angeles, CA 90095, USA
}

Correspondence should be addressed to Bruce Ovbiagele, ovibes@ucsd.edu

Received 16 November 2010; Accepted 14 February 2011

Academic Editor: Seppo Lehto

Copyright (C) 2011 Bruce Ovbiagele et al. This is an open access article distributed under the Creative Commons Attribution License, which permits unrestricted use, distribution, and reproduction in any medium, provided the original work is properly cited.

\begin{abstract}
Background. Diabetes mellitus (DM) confers high vascular risk and is a growing national epidemic. We assessed clinical characteristics and prevalence of diagnosed DM among patients hospitalized with acute myocardial infarction (AMI) in the US over the last decade. Methods. Data were obtained from all states within the US that contributed to the Nationwide Inpatient Sample. All patients admitted to hospitals between 1997 and 2006 with a primary discharge diagnosis of AMI were included. Time trends in the proportion of these patients with DM diagnosis were computed. Results. The portion of patients with comorbid diabetes among AMI hospitalizations increased substantially from 18\% in 1997 to $30 \%$ in $2006(P<.0001)$. Absolute numbers of AMI hospitalizations in the US decreased $8 \%$ (from 729,412 to 672,243 ), while absolute numbers of AMI hospitalizations with coexisting DM rose 51\% $((131,189$ to 198,044$)$, both $(P<.0001)$. Women with AMI were significantly more likely to have DM than similarly aged men, but these differences diminished with increasing age. Conclusion. Although overall hospitalizations for AMI in the US diminished over the last decade, prevalence of diabetes rose substantially. This may have important consequences for the future societal vascular disease burden.
\end{abstract}

\section{Introduction}

Diabetes mellitus is strongly linked to cardiovascular disease [1]. Prevalence of diabetes in the general US population is steadily increasing with recent data indicating that $7.7 \%$ of adults have diagnosed diabetes [2]. The growing national obesity epidemic is expected to result in an even greater rise in the number of individuals in the United States (US) diagnosed with type II diabetes mellitus (DM) [3]. However, there is a paucity of national data on recent patterns and factors associated with diabetes among persons with incident cardiovascular events. Incident coronary heart disease, the principal cause of death among diabetic patients, is especially of interest in this regard.

Greater insights into the evolving prevalence of diabetes among patients experiencing major vascular events encountered in routine clinical practice may be of major public health and economic relevance, especially on a national level, thereby raising awareness and facilitating options for broadly enhancing outcomes in such persons at high vascular risk [4]. The objective of this study was twofold. First, we aimed to assess recent time trends in the prevalence of clinically diagnosed diabetes mellitus among unselected persons hospitalized in the US with an acute myocardial infarction (AMI). Second, we set out to examine the independent relationship between sociodemographic, hospital, and clinical factors and coexisting diabetes mellitus in patients hospitalized for AMI.

\section{Methods}

Data were obtained from the Nationwide Inpatient Sample (NIS), which approximates a stratified 20\% sample of all non-Federal, short-term, general, and specialty hospitals serving adults in the United States. Detailed 


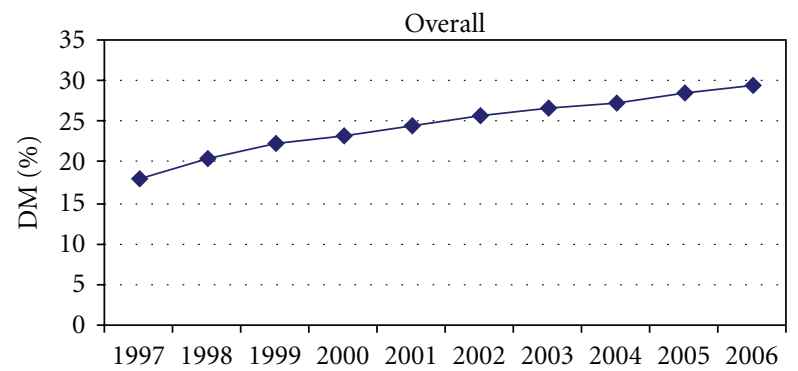

FIGURE 1: Overall trends in proportion of patients with a comorbid diagnosis of diabetes among persons hospitalized with acute myocardial infarction (AMI) in the United States (US) population 1997-2006: trend $P$ value <.001.

information on the design of the NIS is available at http://www.hcup-us.ahrq.gov/. From 1997 to 2006, NIS captured discharge-level information on several million discharges each year. A unique hospital identifier allows for linkage of discharge data to an NIS data set with hospital characteristics.

All patients with a primary diagnosis of AMI were included whether they were alive or dead at the time of discharge. This was done by identifying all discharges with a primary ICD9-CM code of 410.xx (acute myocardial infarction). For patients with $>1$ reported code, only the first reported code was included to avoid double counting patients with multiple reported codes. Total number of AMI hospitalizations was obtained by summing across codes [5].

We computed the weighted proportion of AMI hospitalizations that occurred in persons who had a comorbid diagnosis of diabetes mellitus across the 10-year study period. To identify patients with diabetes mellitus, we used ICD 9-CM codes 250.0-250.9 with a fifth digit 0 or 2 (type II or maturity-onset). As such, codes with a fifth digit 1 or 3 (type I diabetes mellitus) were excluded from the analyses [6]. This approach has been taken before and for the purposes of this study was done to include the type of diabetes known to be strongly connected to obesity [6]. To assess whether there were significant linear trends across time, we included year as a continuous variable in the logistic regression models while adjusting for the NIS survey design. Univariate logistic regression adjusted for the survey design variables was used to evaluate sociodemographic, hospitallevel, and clinical predictors one at a time (unadjusted analysis). To evaluate the independent association of these factors with presence of comorbid diagnosis, of diabetes we used multivariable logistic regression modeling after adjustment for the survey design variables. In the first multivariable model, sociodemographic (age, sex, race) and hospital factors (hospital region, AMI number of hospitalizations, number of beds, and hospital location/teaching status) were adjusted for. The second multivariable model adjusted for the variables in model 1 in addition to clinical factors (i.e., comorbid conditions).

In the aforementioned models, the effect of time was modeled using five 2-year time intervals from 1997/98 to $2005 / 06$. Since we determined that there was a nonlinear/non-monotone relation between age and the odds of coexisting diabetes, we used 5 age categories in 10-year increments $(<55,55-64,65-74,75-84,>84)$ rather than including age as a continuous variable in the models. In addition, since the preliminary unadjusted analyses indicated that the effect of sex differed by age, these age by sex interaction effects were taken into account by including the sex $*$ age group interaction terms in the models. The odds ratios for the effects of sex and age were computed using linear contrasts under the above models. All data analyses were conducted using SAS (version 9.1; SAS Institute Inc, Cary, NC). Statistical hypotheses were tested using $P<.05$ as the level of statistical significance.

\section{Results}

The estimated annual absolute numbers of primary acute MI hospitalizations in the US based on weighted data from 1997 to 2006 are shown in Table 1. Over the 10-year study period, the actual number of total primary AMI diagnoses in the United States generally declined, with 57,169 fewer AMIs (7.8\% relative decrease) in 2006 compared to 1997, $P<.0001$ (Table 1). However, total primary AMI diagnoses among persons with comorbid diabetes generally rose (Table 1), with 66,855 more AMIs (51\% relative rise) in 2006 compared to 1997 . Hospitalized primary AMI patients with comorbid DM (Figure 1) constituted 18\% in 1997 versus 30\% in 2006 $(P<.0001)$.

Increases in prevalence of DM among AMI patients were seen in all age groups regardless of sex (Supplementary Tables 1 and 2 available online at doi:10.4061/2011/145615). There were significant effects by sex, which varied by age group (Figure 2 ). In particular, all women aged $<84$ years were more likely to have DM than similarly aged men, but these effects were most pronounced in the youngest age group ( $<55$ years) and were decreasingly less pronounced in older age groups. After the age of 84, women and men were equally likely to have a comorbid DM diagnosis. It should also be noted, that while the percentage with DM increased across the study period in both men and women, the rate of increase appears to be slightly greater in women aged $<65$ compared to similarly aged men (Figure 2).

Table 2 displays descriptive summary statistics (only results for years 1997 and 2006 are shown) for patients hospitalized with primary AMI who had comorbid diabetes. These results were broadly comparable across several variables. Of note, there were also changes of greater than 10 percentage points across the decade in the following variables: decrease in patients of White race, rise in patients encountered at urban teaching hospitals; greater prevalence of hypertension and renal disease. Median duration of hospitalization lessened by one day (4.4 versus 3.3 days).

Table 3 displays results for the relation between various factors and the odds of comorbid diagnosis of diabetes in patients primarily hospitalized with AMI. There was a significant decrease in the odds of having DM at earlier time intervals (versus later timepoints). Women aged $<84$ years 
TABLE 1: Trends in overall hospital-based primary acute myocardial infarction (AMI) diagnoses in persons with prevalent diabetes mellitus in the United States: 1997-2006.

\begin{tabular}{|c|c|c|c|c|}
\hline Year & Weighted total number of AMI & Number with DM & Percent with DM & Standard error \\
\hline 1997 & 729412 & 131189 & $17.99 \%$ & $0.22 \%$ \\
\hline 1998 & 748368 & 152885 & $20.43 \%$ & $0.20 \%$ \\
\hline 1999 & 726342 & 161319 & $22.21 \%$ & $0.23 \%$ \\
\hline 2000 & 764999 & 178878 & $23.38 \%$ & $0.22 \%$ \\
\hline 2001 & 771910 & 188468 & $24.42 \%$ & $0.22 \%$ \\
\hline 2002 & 762893 & 196742 & $25.79 \%$ & $0.24 \%$ \\
\hline 2003 & 748750 & 199743 & $26.68 \%$ & $0.30 \%$ \\
\hline 2004 & 694297 & 189719 & $27.33 \%$ & $0.32 \%$ \\
\hline 2005 & 661456 & 189134 & $28.59 \%$ & $0.29 \%$ \\
\hline 2006 & 672243 & 198044 & $29.46 \%$ & $0.32 \%$ \\
\hline
\end{tabular}

AMI: acute myocardial infarction; DM: diabetes mellitus.

were more likely to have DM than similarly aged men, but as previously noted these sex effects were greater in younger age groups. Men aged $>55$ had an increase in the odds of having DM compared to men aged $<55$, but generally there appeared to be an inverted $U$ shaped relation with age. The greatest increase in the odds of having DM was observed in men aged $65-74$ (versus $<55$ ), whereas men aged $>84$ were more similar to men aged $<55$. Women aged $>84$ years had a decrease in the odds of having comorbid DM versus women aged $<55$ years, an opposite relationship to that seen in men.

In unadjusted analysis, non-White race was associated with an increase in odds of having a diagnosis of DM, while private/other payer types and South region were associated with a lower likelihood (Table 3 ). Medical conditions associated with greater odds of comorbid DM diagnosis were congestive heart failure, peripheral vascular disease, cerebrovascular disease, renal disease, and hypertension (Table 3). Both multivariable models (Table 3 ) produced similar odds ratio estimates and were consistent with the directions of the unadjusted analysis except for a few differences (odds ratios for age $>84$ versus $<55$ years in men and for age $75-84$ versus $<55$ in women changed direction after adjustment for clinical factors). It should be noted that after adjustment of other factors, West region was associated with decreased odds of having DM.

\section{Discussion}

We found that over the last decade, there was a significant absolute rise of $12 \%$ in the prevalence of DM among patients hospitalized for AMI in the United States. The rise occurred in the setting of an eight percent decrease in the number of overall AMI hospitalizations in 2006 (versus 1997) and a 51 percent increase in actual numbers of AMI hospitalizations with coexisting diabetes in 2006 (versus 1997). Although it is widely recognized that several countries around the world are in the midst of a diabetes epidemic [7], and a major city in the US reported a recent sharp increase in diabetic patients hospitalized for myocardial infarction [8], this recent nationwide boost in prevalence among patients experiencing incident coronary heart disease, the major killer of individuals with DM [9-11], may be of major public health concern especially if it threatens the declining national trend in coronary artery disease events.

Prevalence data for DM among AMI patients across countries and populations from prior studies conducted in the 1980s and 1990s ranged from 10 to $24 \%[9,12,13]$. In the general US adult population, the prevalence of diagnosed diabetes rose from $5.1 \%$ in $1988-1994$ to $7.7 \%$ in 2005 2006 [2]. In comparison, our study showed that in the US, prevalence of DM among AMI patients has increased to a greater degree than in the general population and is now four times more frequent in AMI patients. The precise reasons for the rise in patients hospitalized for AMI with comorbid DM cannot be readily garnered from this study based on an administrative dataset. However, based on prior data [10], recent information [14, 15], and some speculation, the increasingly higher DM prevalence rates noted in this nationwide study of AMI patients likely reflect a combination of factors including the higher risk of AMI in patients with DM, a true rise in the prevalence of DM in the setting of higher rates of obesity and sedentary lifestyle [16], better diagnostic techniques, improved documentation (heightened awareness of diabetes as a coronary risk factor may have resulted in increased testing for diabetes and more complete reporting of diabetes), and prolonged survival. A recent meta-analysis suggests that DM imparts a doubling of the AMI risk, independent of other vascular risk factors [17]. The exact contributions of each of these factors may be hard to determine, but to the extent that there has probably been a real increase in diabetes among these high-vascular risk patients, policy makers at all levels may want to intensify efforts to prevent and optimally control diabetes, especially in the AMI patients we identified as being at higher odds of having comorbid DM.

One such group of patients as noted in our study may be young and middle-aged women. We found a higher prevalence of DM among women with AMI compared to their aged-matched male counterparts, a difference which lessened with increasing age, but which was most apparent among AMI patients $<55$ years. Furthermore, the rate of 


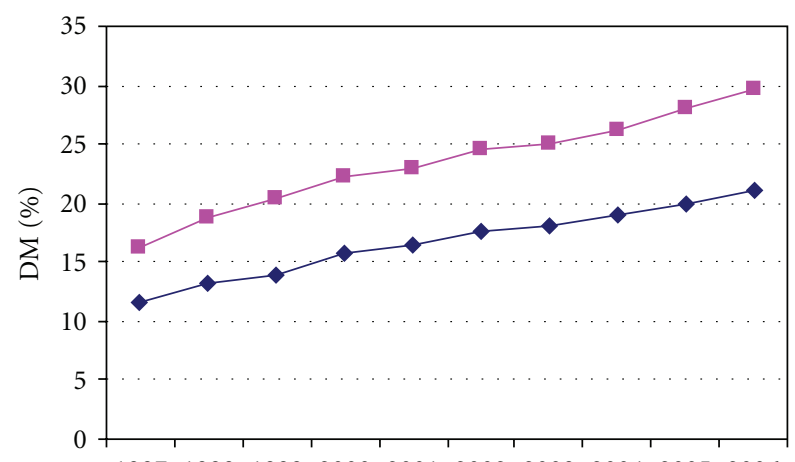

1997199819992000200120022003200420052006

$\rightarrow$ Men $<55$

$\rightarrow$ Women $<55$

(a)

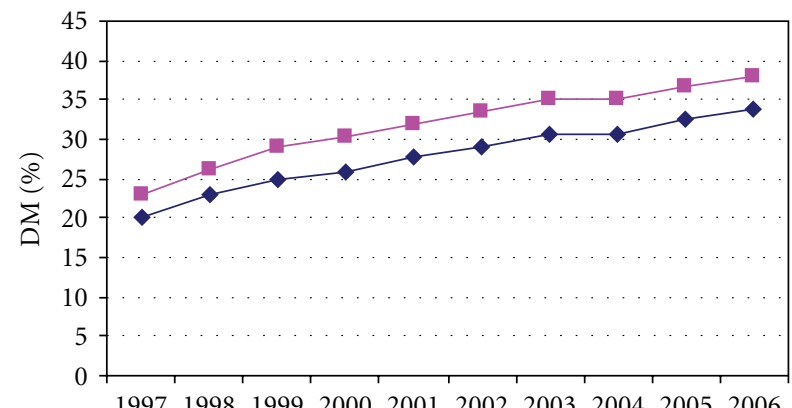

$\multimap$ Men 65-74

$\rightarrow$ Women $65-74$

(c)

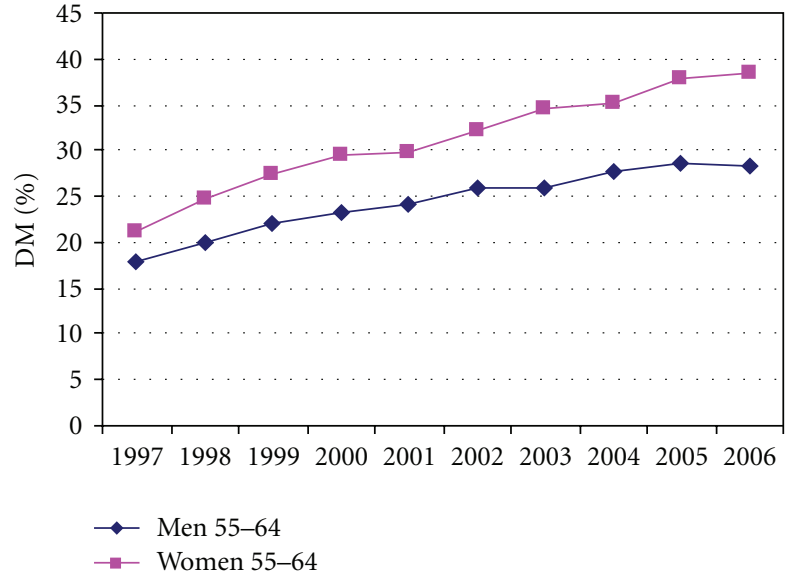

(b)

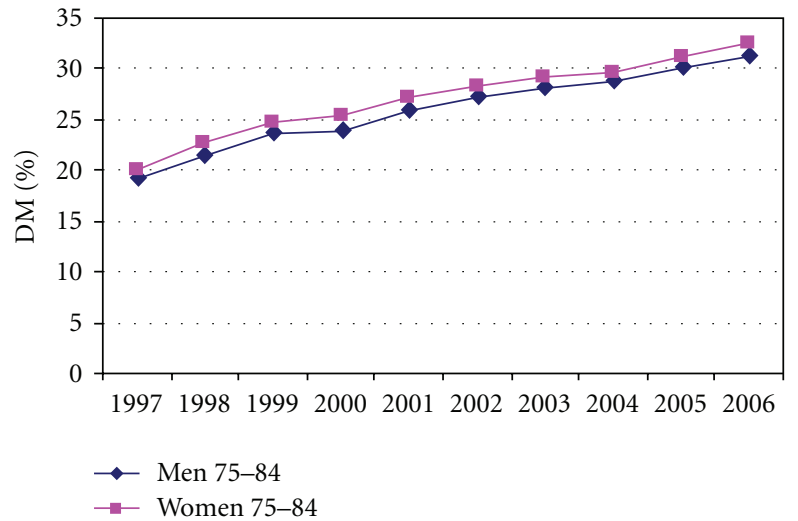

(d)

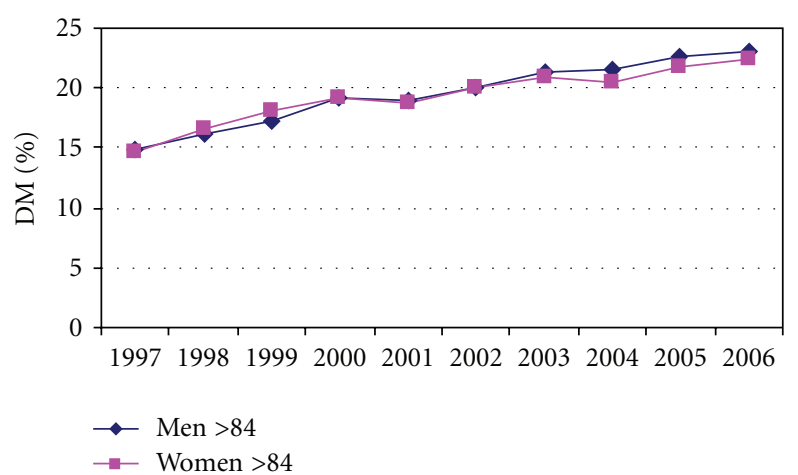

(e)

FIGURE 2: Overall trends in proportion of patients with a comorbid diagnosis of diabetes by age and sex among persons hospitalized with acute myocardial infarction (AMI) in the United States (US) population 1997-2006. Incident AMI is on the $x$-axes.

increase in DM prevalence over the decade appeared to be slightly greater in women aged $<65$ years compared to similarly aged men. A disproportionate burden of coronary risk factors and comorbidities among younger women versus their male counterparts has been previously reported [18], but we are unaware of data explicitly presenting the magnitude of differences in DM prevalence among AMI patients for successive age groups after the age of 55 years. Such a major difference in DM prevalence may in part contribute to the well-known higher rates of in-hospital mortality seen in women versus men aged $<60$ years [19-21].

It was interesting to note that hypertension and renal disease diagnoses have also risen substantially over the decade. Again these increases likely have a multifactorial basis but conceivably also represent some degree of real increase. Both these medical conditions are of course strongly related to presence of diabetes [22] and indeed were among the strongest independent predictors of DM diagnosis in 
TABLE 2: Descriptive summary table for persons with prevalent diabetes mellitus hospitalized primarily with a diagnosis of acute myocardial infarction in the United States: 1997 versus 2006.

\begin{tabular}{|c|c|c|c|c|c|c|c|c|c|}
\hline \multirow{2}{*}{ Variable } & \multirow{2}{*}{ Description } & \multicolumn{3}{|c|}{ Year $1997(n=131,189)$} & \multicolumn{5}{|c|}{ Year $2006(n=198,043)$} \\
\hline & & $\begin{array}{c}\text { Sample } \\
\text { frequency }\end{array}$ & $\begin{array}{l}\text { Weighted } \\
\text { frequency }\end{array}$ & $\begin{array}{c}\text { Weighted } \\
\text { percent }\end{array}$ & SE & $\begin{array}{c}\text { Sample } \\
\text { frequency }\end{array}$ & $\begin{array}{l}\text { Weighted } \\
\text { frequency }\end{array}$ & $\begin{array}{c}\text { Weighted } \\
\text { percent }\end{array}$ & SE \\
\hline \multirow{2}{*}{ Sex } & Male & 15283 & 74592 & 56.9 & 0.4 & 22986 & 112055 & 56.6 & 0.4 \\
\hline & Female & 11517 & 56597 & 43.1 & 0.4 & 17574 & 85988 & 43.4 & 0.4 \\
\hline \multirow{4}{*}{ Race } & White & 17959 & 87457 & 66.7 & 1.7 & 22021 & 107674 & 54.4 & 2.0 \\
\hline & Black & 1923 & 9422 & 7.2 & 0.6 & 3357 & 16289 & 8.2 & 0.6 \\
\hline & Other & 2189 & 10228 & 7.8 & 0.7 & 5360 & 25731 & 13.0 & 1.0 \\
\hline & Unknown & 4729 & 24081 & 18.4 & 1.8 & 9822 & 48349 & 24.4 & 2.2 \\
\hline \multirow{4}{*}{ Hospital region } & North East & 6447 & 32397 & 24.7 & 1.5 & 7979 & 42120 & 21.3 & 1.5 \\
\hline & Mid-West & 6024 & 30406 & 23.2 & 1.4 & 8583 & 43651 & 22.0 & 1.4 \\
\hline & South & 10100 & 48833 & 37.2 & 1.6 & 17191 & 80211 & 40.5 & 1.7 \\
\hline & West & 4229 & 19554 & 14.9 & 0.8 & 6807 & 32061 & 16.2 & 1.0 \\
\hline \multirow{3}{*}{ Location and status } & Rural & 3951 & 19958 & 15.2 & 0.9 & 4178 & 21280 & 10.7 & 0.8 \\
\hline & Urban nonteaching & 13470 & 64299 & 49.0 & 1.6 & 17238 & 81061 & 40.9 & 1.7 \\
\hline & Urban teaching & 9379 & 46932 & 35.8 & 1.7 & 19144 & 95702 & 48.3 & 1.7 \\
\hline \multirow{3}{*}{ Admission source } & Emergency & 16442 & 80117 & 63.1 & 1.6 & 25478 & 124419 & 63.0 & 1.6 \\
\hline & Another health facility & 4909 & 24157 & 19.0 & 1.4 & 8169 & 39909 & 20.2 & 1.3 \\
\hline & Routine & 4513 & 22617 & 17.8 & 1.0 & 6816 & 33232 & 16.8 & 1.1 \\
\hline \multirow{14}{*}{ Comorbid condition } & Hypertension & 15483 & 75669 & 57.7 & 0.4 & 30846 & 150463 & 76.0 & 0.4 \\
\hline & CVD & 1791 & 8782 & 6.7 & 0.2 & 2626 & 12824 & 6.5 & 0.2 \\
\hline & Atrial fibrillation & 4238 & 20695 & 15.8 & 0.3 & 6584 & 32288 & 16.3 & 0.3 \\
\hline & Valvular disease & 3459 & 16804 & 12.8 & 0.5 & 5389 & 26307 & 13.3 & 0.4 \\
\hline & Congestive heart failure & 10808 & 52957 & 40.4 & 0.5 & 16114 & 78774 & 39.8 & 0.5 \\
\hline & PVD & 2177 & 10599 & 8.1 & 0.2 & 4325 & 21167 & 10.7 & 0.4 \\
\hline & Dementia & 410 & 2012 & 1.5 & 0.1 & 813 & 4013 & 2.0 & 0.1 \\
\hline & $\mathrm{CPD}$ & 4288 & 21044 & 16.0 & 0.3 & 8948 & 43698 & 22.1 & 0.4 \\
\hline & Mild liver disease & 156 & 732 & 0.6 & 0.0 & 4849 & 23670 & 12.0 & 0.3 \\
\hline & Mod/severe liver disease & 28 & 127 & 0.1 & 0.0 & 57 & 274 & 0.1 & 0.0 \\
\hline & Renal disease & 1696 & 8322 & 6.3 & 0.2 & 8526 & 41660 & 21.0 & 0.4 \\
\hline & Cancer & 452 & 2197 & 1.7 & 0.1 & 881 & 4335 & 2.2 & 0.1 \\
\hline & Metastatic cancer & 121 & 561 & 0.4 & 0.0 & 229 & 1132 & 0.6 & 0.0 \\
\hline & & \multicolumn{3}{|c|}{ Median } & \multicolumn{5}{|c|}{ Median } \\
\hline Stay length & Days & \multicolumn{3}{|c|}{4.4} & \multicolumn{5}{|c|}{3.3} \\
\hline Age & Years & \multicolumn{3}{|c|}{69.6} & \multicolumn{5}{|c|}{68.1} \\
\hline
\end{tabular}

SE: standard error; CVD: cerebrovascular disease; PVD: peripheral vascular disease; CPD: chronic pulmonary disease; Emergency: patient first admitted via emergency department. Another health facility: patient transferred from nursing home or other ancillary nonacute care health facility. Routine: scheduled nonmergent admission, typically directly from home, or outpatient program. Cancer: total number of patients with cancer (including metastatic cancers).

our study. Other factors independently linking co-existent DM with incident AMI in our multivariable analyses were female sex, non-White race, and comorbid systemic vascular damage have been noted in other studies [23-26].

Consistent with other studies, there was an overall decline in the absolute number of AMI hospitalizations during the study period $[27,28]$. In recent study, the annual AMI hospitalization rate in the fee-for-service population fell from 1131 per 100000 beneficiary-years in 2002 to 866 in 2007 , a relative $23.4 \%$ decline. The apparent reduction in AMI hospitalization may be attributed to decrease in certain CV risk factors, greater use of cardiovascular protective medications, and improvements in coronary revascularization. However, had there not been such a large temporal increase in the prevalence of DM, the reduction in AMI hospitalizations during this time period may have been even more pronounced.

This study has limitations. First, we cannot exclude possible inaccurate reporting of ICD codes. However, the ICD-9 diagnosis-coded case definitions have been consistently well validated in previous studies using the same or similar hospitalization data [29]. Further, any potential 
TABLE 3: Factors associated with comorbid diabetes mellitus diagnosis in patients hospitalized primarily for acute myocardial infarction in the United States between 1997-2006.

\begin{tabular}{|c|c|c|c|c|c|c|c|c|c|c|c|c|}
\hline \multirow[t]{2}{*}{ Variable } & \multicolumn{4}{|c|}{ Unadjusted } & \multicolumn{4}{|c|}{ Multivariable model no. 1} & \multicolumn{4}{|c|}{ Multivariable model no. 2} \\
\hline & OR & $\begin{array}{c}\text { Lower } \\
95 \% \text { CL }\end{array}$ & $\begin{array}{c}\text { Upper } \\
95 \% \text { CL }\end{array}$ & $P$-value & OR & $\begin{array}{c}\text { Lower } \\
95 \% \mathrm{CL}\end{array}$ & $\begin{array}{c}\text { Upper } \\
95 \% \text { CL }\end{array}$ & $P$-value & OR & $\begin{array}{c}\text { Lower } \\
95 \% \text { CL }\end{array}$ & $\begin{array}{c}\text { Upper } \\
95 \% \text { CL }\end{array}$ & $P$-value \\
\hline \multicolumn{13}{|l|}{ Year } \\
\hline $1997-1998$ versus $2005-2006$ & 0.58 & 0.57 & 0.60 & $<.0001$ & 0.57 & 0.56 & 0.59 & $<.0001$ & 0.63 & 0.61 & 0.64 & $<.0001$ \\
\hline $1999-2000$ versus $2005-2006$ & 0.72 & 0.70 & 0.74 & $<.0001$ & 0.72 & 0.70 & 0.73 & $<.0001$ & 0.77 & 0.75 & 0.79 & $<.0001$ \\
\hline 2001-2002 versus $2005-2006$ & 0.82 & 0.80 & 0.84 & $<.0001$ & 0.81 & 0.80 & 0.83 & $<.0001$ & 0.86 & 0.84 & 0.88 & $<.0001$ \\
\hline 2003-2004 versus 2005-2006 & 0.90 & 0.88 & 0.93 & $<.0001$ & 0.89 & 0.87 & 0.91 & $<.0001$ & 0.92 & 0.89 & 0.94 & $<.0001$ \\
\hline \multicolumn{13}{|l|}{ Demographics } \\
\hline Female versus male in $<55$ & 1.54 & 1.51 & 1.57 & $<.0001$ & 1.46 & 1.43 & 1.49 & $<.0001$ & 1.42 & 1.39 & 1.45 & $<.0001$ \\
\hline Female versus male in 55-64 & 1.41 & 1.38 & 1.43 & $<.0001$ & 1.33 & 1.31 & 1.36 & $<.0001$ & 1.28 & 1.25 & 1.30 & $<.0001$ \\
\hline Female versus male in $65-74$ & 1.21 & 1.19 & 1.23 & $<.0001$ & 1.18 & 1.16 & 1.20 & $<.0001$ & 1.12 & 1.10 & 1.14 & $<.0001$ \\
\hline Female versus male in $75-84$ & 1.06 & 1.05 & 1.08 & $<.0001$ & 1.05 & 1.03 & 1.06 & $<.0001$ & 1.00 & 0.98 & 1.02 & .8970 \\
\hline Female versus male in $>84$ & 0.99 & 0.96 & 1.01 & .3592 & 0.98 & 0.95 & 1.01 & .1160 & 0.92 & 0.90 & 0.95 & $<.0001$ \\
\hline Age $55-64$ versus $<55$ in $M$ & 1.62 & 1.59 & 1.64 & $<.0001$ & 1.62 & 1.60 & 1.65 & $<.0001$ & 1.51 & 1.48 & 1.53 & $<.0001$ \\
\hline Age $65-74$ versus $<55$ in $\mathrm{M}$ & 1.94 & 1.90 & 1.98 & $<.0001$ & 1.66 & 1.62 & 1.69 & $<.0001$ & 1.52 & 1.48 & 1.55 & $<.0001$ \\
\hline Age $75-84$ versus $<55$ in $M$ & 1.76 & 1.73 & 1.79 & $<.0001$ & 1.49 & 1.45 & 1.52 & $<.0001$ & 1.30 & 1.27 & 1.33 & $<.0001$ \\
\hline Age $>84$ versus $<55$ in $M$ & 1.21 & 1.18 & 1.24 & $<.0001$ & 1.02 & 0.99 & 1.05 & .2905 & 0.85 & 0.83 & 0.88 & $<.0001$ \\
\hline Age $55-64$ versus $<55$ in $F$ & 1.48 & 1.44 & 1.51 & $<.0001$ & 1.48 & 1.44 & 1.51 & $<.0001$ & 1.36 & 1.33 & 1.39 & $<.0001$ \\
\hline Age $65-74$ versus $<55$ in $F$ & 1.53 & 1.49 & 1.56 & $<.0001$ & 1.33 & 1.30 & 1.37 & $<.0001$ & 1.20 & 1.17 & 1.23 & $<.0001$ \\
\hline Age $75-84$ versus $<55$ in $F$ & 1.22 & 1.19 & 1.24 & $<.0001$ & 1.07 & 1.04 & 1.10 & $<.0001$ & 0.92 & 0.89 & 0.94 & $<.0001$ \\
\hline Age $>84$ versus $<55$ in $\mathrm{F}$ & 0.78 & 0.76 & 0.80 & $<.0001$ & 0.68 & 0.66 & 0.70 & $<.0001$ & 0.55 & 0.54 & 0.57 & $<.0001$ \\
\hline Race: Black versus White & 1.52 & 1.49 & 1.55 & $<.0001$ & 1.50 & 1.47 & 1.54 & $<.0001$ & 1.27 & 1.24 & 1.29 & $<.0001$ \\
\hline Race: Other versus White & 1.72 & 1.66 & 1.78 & $<.0001$ & 1.75 & 1.69 & 1.80 & $<.0001$ & 1.62 & 1.58 & 1.67 & $<.0001$ \\
\hline Race: Unknown versus White & 1.00 & 0.97 & 1.02 & .9365 & 0.99 & 0.97 & 1.02 & .5642 & 0.99 & 0.97 & 1.01 & .4811 \\
\hline \multicolumn{13}{|l|}{ Hospital characteristics } \\
\hline Midwest versus northeast & 0.97 & 0.93 & 1.00 & .0562 & 1.03 & 0.99 & 1.06 & .1227 & 1.03 & 1.00 & 1.06 & .0608 \\
\hline South versus northeast & 0.94 & 0.91 & 0.97 & .0002 & 0.93 & 0.90 & 0.95 & $<.0001$ & 0.93 & 0.90 & 0.96 & $<.0001$ \\
\hline West versus northeast & 0.99 & 0.95 & 1.04 & .7998 & 0.96 & 0.93 & 0.99 & .0228 & 0.96 & 0.93 & 0.99 & .0207 \\
\hline Medium versus small bed size* & 1.00 & 0.97 & 1.03 & .9390 & 1.01 & 0.98 & 1.04 & .5717 & 1.00 & 0.98 & 1.03 & .8447 \\
\hline Large versus small bed size* & 0.97 & 0.95 & 1.00 & .0698 & 0.99 & 0.96 & 1.02 & .6759 & 0.98 & 0.95 & 1.01 & .2078 \\
\hline Volume** quartile: 2 versus 1 & 1.11 & 1.06 & 1.16 & $<.0001$ & 1.08 & 1.03 & 1.13 & .0022 & 1.04 & 0.99 & 1.09 & .1432 \\
\hline Volume** quartile: 3 versus 1 & 1.12 & 1.06 & 1.17 & $<.0001$ & 1.09 & 1.03 & 1.15 & .0015 & 1.03 & 0.98 & 1.08 & .3058 \\
\hline Volume** quartile: 4 versus 1 & 1.03 & 0.98 & 1.07 & .2739 & 1.02 & 0.96 & 1.08 & .5026 & 0.97 & 0.92 & 1.03 & .3615 \\
\hline Urban nonteaching versus rural & 0.96 & 0.93 & 0.99 & .0078 & 0.96 & 0.93 & 1.00 & .0286 & 0.94 & 0.91 & 0.97 & .0001 \\
\hline Urban teaching versus rural & 0.98 & 0.95 & 1.02 & .3058 & 0.97 & 0.94 & 1.01 & .1820 & 0.95 & 0.91 & 0.98 & .0037 \\
\hline \multicolumn{13}{|l|}{ Comorbid conditions } \\
\hline Congestive heart failure & 1.61 & 1.59 & 1.63 & $<.0001$ & & & & & 1.67 & 1.65 & 1.69 & $<.0001$ \\
\hline Peripheral vascular disease & 1.46 & 1.43 & 1.49 & $<.0001$ & & & & & 1.26 & 1.24 & 1.28 & $<.0001$ \\
\hline Cerebrovascular disease & 1.25 & 1.23 & 1.27 & $<.0001$ & & & & & 1.10 & 1.08 & 1.12 & $<.0001$ \\
\hline Dementia & 0.92 & 0.89 & 0.95 & $<.0001$ & & & & & 0.96 & 0.93 & 0.99 & .0062 \\
\hline Chronic pulmonary disease & 0.93 & 0.92 & 0.94 & $<.0001$ & & & & & 0.81 & 0.80 & 0.82 & $<.0001$ \\
\hline Mild liver disease & 0.93 & 0.89 & 0.97 & .0004 & & & & & 0.90 & 0.86 & 0.94 & $<.0001$ \\
\hline Renal disease & 1.89 & 1.85 & 1.93 & $<.0001$ & & & & & 1.32 & 1.30 & 1.35 & $<.0001$ \\
\hline Cancer & 0.82 & 0.80 & 0.84 & $<.0001$ & & & & & 0.84 & 0.82 & 0.87 & $<.0001$ \\
\hline Mod/severe liver disease & 1.04 & 0.94 & 1.16 & .4229 & & & & & 1.03 & 0.92 & 1.15 & .5980 \\
\hline Metastatic carcinoma & 0.72 & 0.69 & 0.76 & $<.0001$ & & & & & 0.79 & 0.75 & 0.83 & $<.0001$ \\
\hline Valvular disease & 0.91 & 0.90 & 0.93 & $<.0001$ & & & & & 0.82 & 0.81 & 0.83 & $<.0001$ \\
\hline Atrial fibrilation & 0.93 & 0.92 & 0.94 & $<.0001$ & & & & & 0.87 & 0.86 & 0.88 & $<.0001$ \\
\hline Hypertension & 1.98 & 1.96 & 2.01 & $<.0001$ & & & & & 1.84 & 1.82 & 1.86 & $<.0001$ \\
\hline
\end{tabular}

${ }^{*}$ Number of short-term acute beds in a hospital. Please see full bed categorization at http://www.hcup-us.ahrq.gov/db/vars/hosp_bedsize/nisnote.jsp

**Number of AMI hospitalizations per year for a given hospital; OR: odds ratio; CL: confidence interval; SAH: subarachnoid hemorrhage; ICH: intracerebral hemorrhage. Multivariable Model no. 1 includes sociodemographic and hospital factors. Multivariable model no. 2 includes sociodemographic, hospital, and clinical factors. Cancer: total number of patients with cancer (including metastatic cancers). Please note Bonferroni correction was not applied. 
reporting errors in this large database were unlikely to have been systematic. Second, detailed patient-level data, such as glucose levels, HbAlc, vascular biomarkers, and medications were not available for our analysis. Third, since up to one-fourth of all persons with diabetes may actually be undiagnosed [30], we may have missed patients with DM who did not have a premorbid history and were not screened during their hospitalization. Fourth, we could not count out hospital AMIs which did not result in hospitalization. While an increase in out-of-hospital sudden cardiac death can potentially explain a decline in AMI hospitalizations, it would not explain the rising prevalence of DM. Finally, the observed rise in DM prevalence may also have been impacted by lowering of the fasting plasma glucose range for diagnosing impaired fasting glucose in 2003 [31], but between years 1997 and 2006, the rate of increase in DM prevalence among AMI patients was relatively constant, suggesting that the change in diagnostic criteria had a minimal effect on DM rates in this population. In addition, the substantially higher rise in DM prevalence among AMI patients versus general population during this time period suggests that this was probably not a major factor. The study benefited from its nationwide scope, standardized methodology, and clinician diagnosed incidence data.

In conclusion, overall risk factor reduction and better treatment of AMI patients has decreased incidence of AMI rates, but we observed a recent steep rise in the number of patients hospitalized for AMI with coexisting DM the United States, a boost that suggests that the population health burden of diabetic coronary heart disease (CHD) remains considerable and might be increasing. Future studies are warranted to confirm these results and explore ways to mitigate this mounting problem, which could exponentially worsen in the years to come, in the face of the growing obesity epidemic.

\section{Disclosures}

Daniela Markovic, M.S. degree, and Bruce Ovbiagele, M.D. and M.S. degrees, had full access to all of the data in the study and take responsibility for the integrity of the data and the accuracy of the data analysis. Gregg Fonarow is a Consultant at Novartis.

\section{Conflict of Interests}

The authors declare that they have no conflicts of interests.

\section{References}

[1] Centers for Disease Control and Prevention, "National diabetes fact sheet: General information and national estimates on diabetes in the united states, 2007," U.S. Department of health and human services, centers for disease control and prevention, Atlanta, Ga, USA, 2008.

[2] C. C. Cowie, K. F. Rust, E. S. Ford et al., "Full accounting of diabetes and pre-diabetes in the U.S. population in 1988-1994 and 2005-2006," Diabetes Care, vol. 32, no. 2, pp. 287-294, 2009.
[3] C. L. Ogden, M. D. Carroll, L. R. Curtin, M. A. McDowell, C. J. Tabak, and K. M. Flegal, "Prevalence of overweight and obesity in the United States, 1999-2004," Journal of the American Medical Association, vol. 295, no. 13, pp. 1549-1555, 2006.

[4] K. M. V. Narayan, E. W. Gregg, A. Fagot-Campagna, M. M. Engelgau, and F. Vinicor, "Diabetes-a common, growing, serious, costly, and potentially preventable public health problem," Diabetes Research and Clinical Practice, vol. 50, supplement 2, pp. S77-S84, 2000.

[5] G. R. Williams, J. G. Jiang, D. B. Matchar, and G. P. Samsa, "Incidence and occurrence of total (first-ever and recurrent) stroke," Stroke, vol. 30, no. 12, pp. 2523-2528, 1999.

[6] S. H. Saydah, L. S. Geiss, E. Tierney, S. M. Benjamin, M. Engelgau, and F. Brancati, "Review of the performance of methods to identify diabetes cases among vital statistics, administrative, and survey data," Annals of Epidemiology, vol. 14, no. 7, pp. 507-516, 2004.

[7] D. Yach, C. Hawkes, C. L. Gould, and K. J. Hofman, "The global burden of chronic diseases: overcoming impediments to prevention and control," Journal of the American Medical Association, vol. 291, no. 21, pp. 2616-2622, 2004.

[8] J. Fang and M. H. Alderman, "Impact of the increasing burden of diabetes on acute myocardial infarction in New York City: 1990-2000,” Diabetes, vol. 55, no. 3, pp. 768-773, 2006.

[9] L. Rytter, S. Troelsen, and H. Beck-Nielsen, "Prevalence and mortality of acute myocardial infarction in patients with diabetes," Diabetes Care, vol. 8, no. 3, pp. 230-234, 1985.

[10] J. M. Sprafka, G. L. Burke, A. R. Folsom, P. G. McGovern, and L. P. Hahn, "Trends in prevalence of diabetes mellitus in patients with myocardial infarction and effect of diabetes on survival: the Minnesota Heart Survey," Diabetes Care, vol. 14, no. 7, pp. 537-543, 1991.

[11] J. Stamler, O. Vaccaro, J. D. Neaton, and D. Wentworth, "Diabetes, other risk factors, and 12-yr cardiovascular mortality for men screened in the multiple risk factor intervention trial," Diabetes Care, vol. 16, no. 2, pp. 434-444, 1993.

[12] K. Malmberg and L. Ryden, "Myocardial infarction in patients with diabetes mellitus," European Heart Journal, vol. 9, no. 3, pp. 259-264, 1988.

[13] V. Lundberg, B. Stegmayr, K. Asplund, M. Eliasson, and F. Huhtasaari, "Diabetes as a risk factor for myocardial infarction: population and gender perspectives," Journal of Internal Medicine, vol. 241, no. 6, pp. 485-492, 1997.

[14] "Prevalence of diabetes and impaired fasting glucose in adults—united states, 1999-2000," Morbidity and Mortality Weekly Report, vol. 52, pp. 833-837, 2003.

[15] E. W. Gregg, Y. J. Cheng, B. L. Cadwell et al., "Secular trends in cardiovascular desease risk factors according to body mass index in US adults," Journal of the American Medical Association, vol. 293, no. 15, pp. 1868-1874, 2005.

[16] J. R. Pender and W. J. Pories, "Epidemiology of obesity in the United States," Gastroenterology Clinics of North America, vol. 34 , no. 1, pp. 1-7, 2005.

[17] The Emerging Risk Factors Collaboration, "Diabetes mellitus, fasting blood glucose concentration, and risk of vascular disease: a collaborative meta-analysis of 102 prospective studies," The Lancet, vol. 375, no. 9733, pp. 2215-2222, 2010.

[18] V. Vaccarino, S. S. Rathore, N. K. Wenger et al., "Sex and racial differences in the management of acute myocardial infarction, 1994 through 2002," New England Journal of Medicine, vol. 353, no. 7, pp. 671-682, 2005.

[19] V. Vaccarino, R. I. Horwitz, T. P. Meehan, M. K. Petrillo, M. J. Radford, and H. M. Krumholz, "Sex differences in mortality after myocardial infarction: evidence for a sex-age 
interaction," Archives of Internal Medicine, vol. 158, no. 18, pp. 2054-2062, 1998.

[20] A. Rosengren, C. L. Spetz, M. Köster, N. Hammar, L. Alfredsson, and M. Rosén, "Sex differences in survival after myocardial infarction in Sweden: data from the Swedish national acute myocardial infarction register," European Heart Journal, vol. 22, no. 4, pp. 314-322, 2001.

[21] G. K. Andrikopoulos, S. E. Tzeis, A. G. Pipilis et al., "Younger age potentiates post myocardial infarction survival disadvantage of women," International Journal of Cardiology, vol. 108, no. 3, pp. 320-325, 2006.

[22] M. R. Movahed, S. Sattur, and M. Hashemzadeh, "Independent association between type 2 diabetes mellitus and hypertension over a period of 10 years in a large inpatient population," Clinical and Experimental Hypertension, vol. 32, no. 3, pp. 198-201, 2010.

[23] K. Gu, C. C. Cowie, and M. I. Harris, "Diabetes and decline in heart disease mortality in US adults," Journal of the American Medical Association, vol. 281, no. 14, pp. 1291-1297, 1999.

[24] R. F. Gillum, M. E. Mussolino, and J. H. Madans, "Diabetes mellitus, coronary heart disease incidence, and death from all causes in african american and european american women: the nhanes i epidemiologic follow-up study," Journal of Clinical Epidemiology, vol. 53, no. 5, pp. 511-518, 2000.

[25] C. Maynard, M. K. Chapko, N. R. Every, D. C. Martin, and J. L. Ritchie, "Coronary angioplasty outcomes in the Healthcare Cost and Utilization Project, 1993-1994," American Journal of Cardiology, vol. 81, no. 7, pp. 848-852, 1998.

[26] E. F. Philbin, P. A. McCullough, T. G. DiSalvo, G. W. Dec, P. L. Jenkins, and W. D. Weaver, "Underuse of invasive procedures among medicaid patients with acute myocardial infarction," American Journal of Public Health, vol. 91, no. 7, pp. 10821088, 2001.

[27] "Quickstats: rate of hospitalizations for coronary atherosclerosis and acute myocardial infarction (mi), by year-national hospital discharge survey, United States, 1996-2005," Morbidity and Mortality Weekly Report, vol. 56, p. 659, 2007.

[28] J. Chen, S. L. T. Normand, Y. Wang, E. E. Drye, G. C. Schreiner, and H. M. Krumholz, "Recent declines in hospitalizations for acute myocardial infarction for medicare fee-for-service beneficiaries: progress and continuing challenges," Circulation, vol. 121, no. 11, pp. 1322-1328, 2010.

[29] L. A. Petersen, S. Wright, S. L. T. Normand, and J. Daley, "Positive predictive value of the diagnosis of acute myocardial infarction in an administrative database," Journal of General Internal Medicine, vol. 14, no. 9, pp. 555-558, 1999.

[30] American Diabetes Association, "Diagnosis and classification of diabetes mellitus," Diabetes Care, vol. 33, pp. S62-S69, 2010.

[31] S. Genuth, K. G. Alberti, P. Bennett et al., "Follow-up report on the diagnosis of diabetes mellitus," Diabetes Care, vol. 26, no. 11, pp. 3160-3167, 2003. 


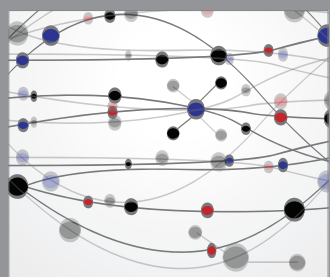

The Scientific World Journal
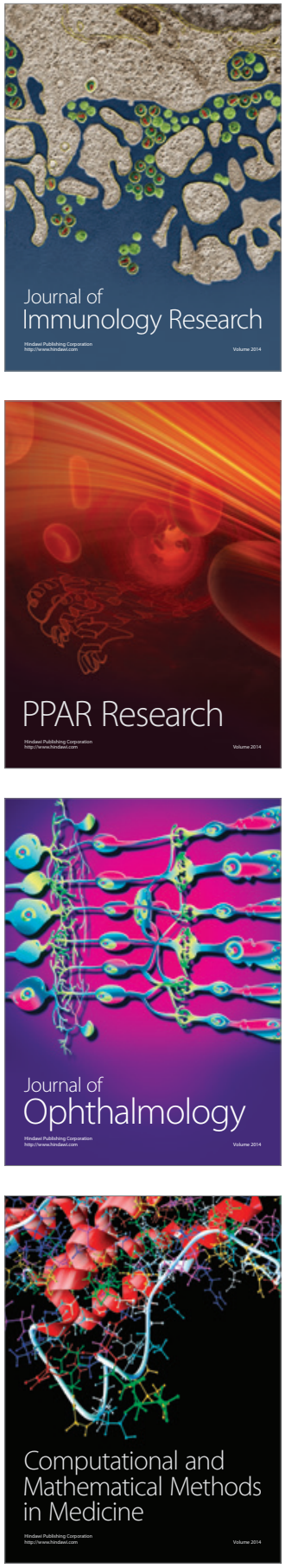

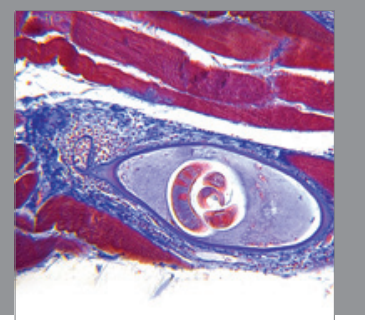

Gastroenterology

Research and Practice
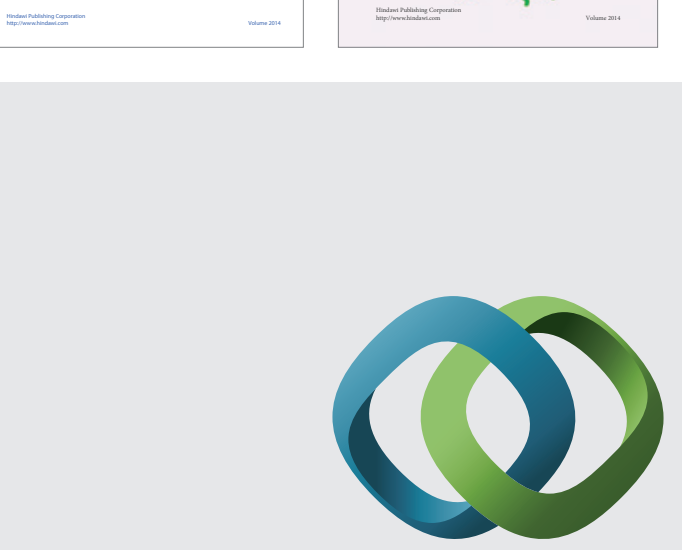

\section{Hindawi}

Submit your manuscripts at

http://www.hindawi.com
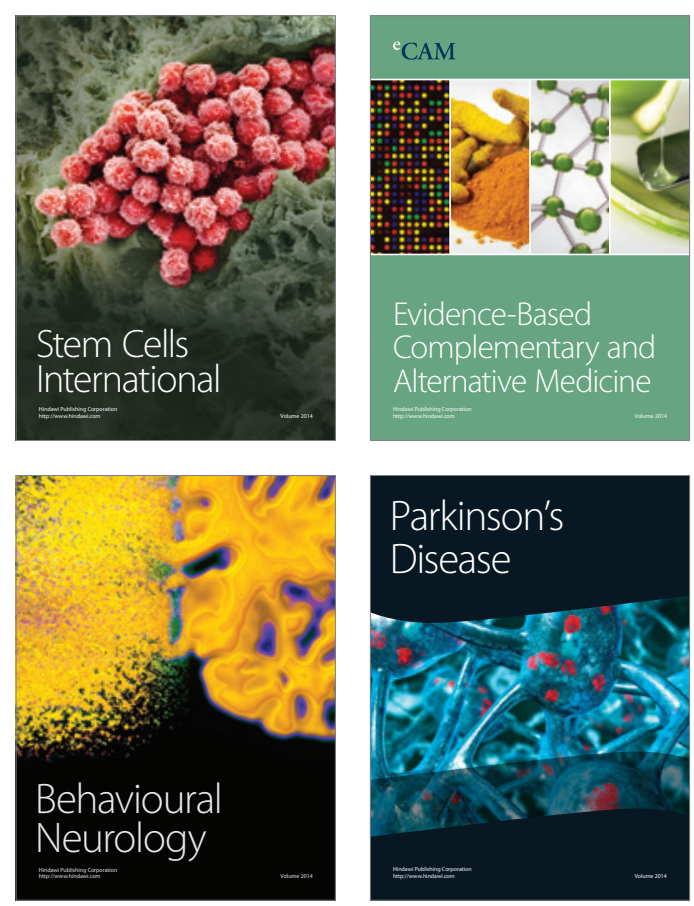

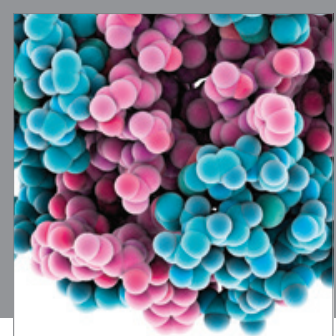

Journal of
Diabetes Research

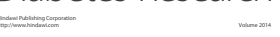

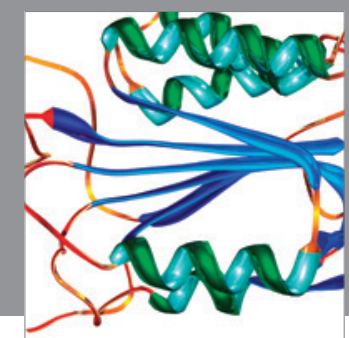

Disease Markers
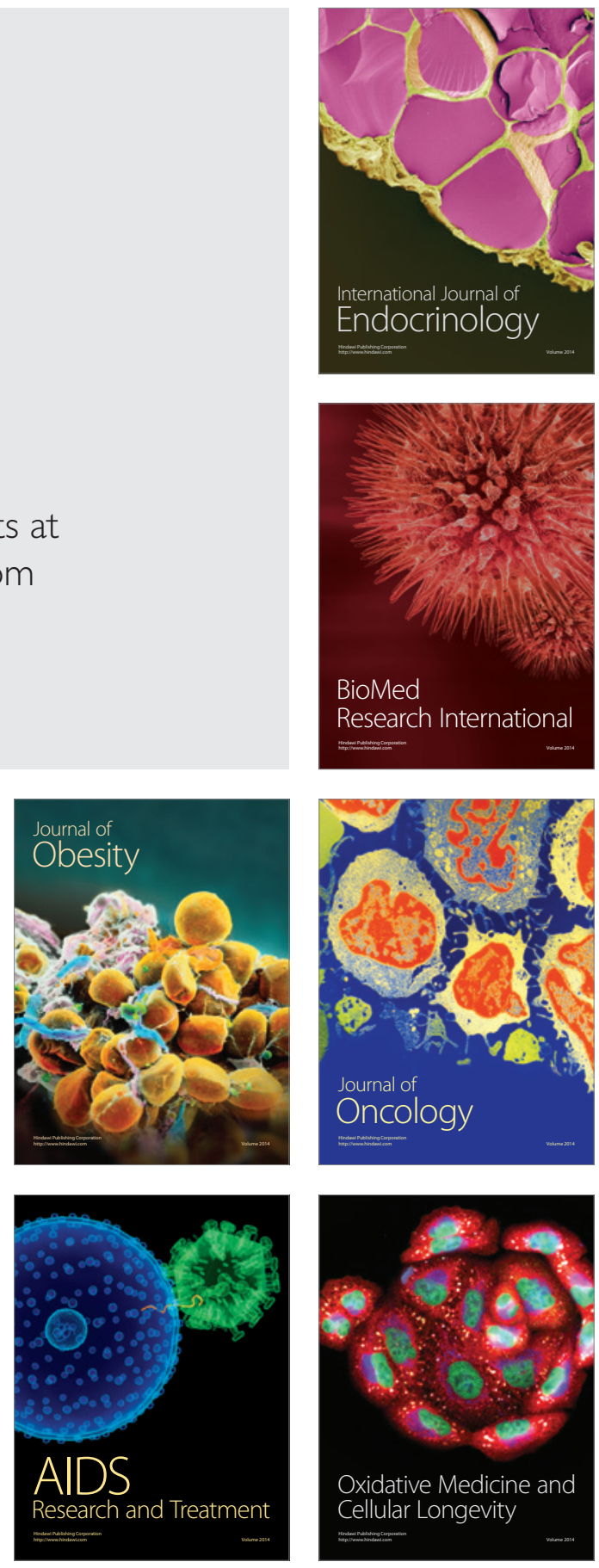